\title{
Relação entre métodos de quantificação de cargas de treinamento baseados em percepção de esforço e frequência cardíaca em jogadores jovens de futsal
}

CDD. 20.ed. 796.073

796.5

\author{
Vinicius Flávio MILANEZ/****** \\ Solange de Paula RAMOS ${ }^{* *}$ \\ Fuad SALLE-NETO*** \\ Fabiana Andrade MACHADO**** \\ Fábio Yuzo NAKAMURA***
}

*Faculdade de Ensino Superior Dom Bosco.

**União das Instituições das Educacionais do Estado de São Paulo

***Universidade Estadual de Londrina. $* * \star *$ Universidade Estadual de Maringá.

\section{Resumo}

Os objetivos do estudo foram verificar a associação entre os métodos de quantificação da carga de treinamento, PSE da sessão e impulso de treinamento proposto por Lucía (Lucia $\left.{ }_{\text {TRIMP }}\right)$ e descrever a distribuição da intensidade de treinamento no futsal semiprofissional da categoria sub 18. Quinze jogadores (média e DP; idade: $17 \pm 1$ ano; massa corporal: 70,4 $\pm 6,5 \mathrm{~kg}$; estatura: $175 \pm 4 \mathrm{~cm}$ e IMC $23 \pm 2 \mathrm{~kg} \cdot \mathrm{m}^{-2}$ ) foram submetidos a um teste de corrida incremental para determinar o limiar ventilatório (LV), o ponto de compensação respiratória (PCR) e o consumo máximo de oxigênio $\left(\mathrm{VO}_{2 \text { max }}\right)$. Apenas oito atletas foram monitorados por meio dos métodos PSE da sessão e Lucia ${ }_{\text {TRIMP }}$ durante 78 sessões de treinamento antes da principal competição da temporada. Foram encontradas correlações individuais de magnitudes alta a quase perfeita $(r=0,64-0,91)$ entre os métodos PSE da sessão e Lucia ${ }_{\text {TRMP }} 0$ padrão de distribuição da intensidade de treinamento foi 76 , 18 e 6\% do tempo abaixo do LV (zona 1), entre LV e PCR (zona 2) e acima do PCR (zona 3), respectivamente. 0 método PSE da sessão se mostrou altamente relacionado com um método objetivo de quantificação da carga de treinamento. Além disso, as sessões de treinamento de uma equipe de futsal semiprofissional da categoria sub 18 apresentaram um padrão decrescente de distribuição das intensidades de treinamento.

UnITERMOS: Limiar ventilatório; Ponto de compensação respiratória; Carga interna de treinamento; Esportes coletivos.

\section{Introdução}

O treinamento elaborado pelos treinadores e preparadores físicos envolve manipulação das cargas de treinamento (CT) para se obter uma resposta fisiológica favorável e consequente aumento no desempenho esportivo (LAMBERT \& BORRESEN, 2010). CT subestimadas para a capacidade individual de absorvê-las podem atenuar as respostas adaptativas favoráveis, assim como, doses superestimadas de carga podem potencializar o risco de lesōes e conduzir o atleta a uma diminuição do desempenho em longo prazo, conhecida como síndrome de overtraining (Meeusen, Duclos, Glesson, Rietjens, Steinacker \& Urhausen, 2006; Nederhof, Zwerver, Brink, Meeusen \& Lemmink, 2008). Dessa forma, o sucesso deste processo depende do monitoramento preciso da carga interna de treinamento (NAKAMURA, MoREIRA \& AOKI, 2010), uma vez que essa variável é um importante componente tanto para o aumento do desempenho (Suzuki, Sato, MaEda \& TAKahashi, 2006), quanto para a prevenção do "overtraining" (Foster, 1998; TAHA \& ThOMAs, 2003).

Para monitorar o estresse fisiológico, ou carga interna de treinamento, existem diversos métodos baseados em impulsos de treinamento (TRIMP), que integram volume e intensidade de exercício, a partir de respostas da frequência cardíaca (FC) (BANISTER, 1991; EDWARDS, 1993; LuCIA, Hoyos, Santalla, Earnest \& Chicharro, 2003; Stagno, 
Thatcher \& van Someren, 2007; Manzi, Castagna, Padua, Lombardo, D'Ottavio, Massaro, Volterrani \& Iellamo, 2009a; Manzi, Iellamo, Impellizzeri, D'OtTaVio \& Castagna, 2009b), da concentração sanguínea de lactato ([La]) (SEILER \& KJERLAND, 2006) e da percepção subjetiva de esforço (PSE) (Foster, Hector, Welsh, Schrager, Green \& SNYDER,1995). Algumas limitaçôes em relação aos métodos baseados nas respostas da FC e da [La] têm sido reportadas na literatura (AlEXIou \& CoutTs 2008; BORRESEN \& LAMBERT, 2008; IMPELLIZZERI, Rampinini, Coutts, Sassi \& Marcora 2004), sobretudo no que diz respeito à quantificação do esforço em modalidades que envolvem atividades intermitentes de alta intensidade.

Por outro lado, o método baseado na resposta da PSE tem se destacado na literatura por sua fácil aplicação e baixo custo operacional (AleXIou \& Coutts, 2008; Borresen \& Lambert, 2008; IMPELLIZZER et al., 2004). A PSE da sessão é um método simples para quantificar a carga interna de treinamento, que consiste na multiplicação da intensidade da sessão, obtida a partir da escala CR10 de percepção de esforço (BORG, HASSMEN \& LAGERSTROM, 1987), posteriormente adaptada por Foster (1998), pela duração da mesma. O produto dessa multiplicação representa o valor da magnitude da carga interna, expresso em unidades arbitrarias (UA) (IMPELLIZZERI et al., 2004).

Estudos reportaram altas correlações entre os métodos baseados na resposta da FC com o método baseado na PSE, em algumas modalidades tais como futebol (Alexiou \& CoutTs, 2008; Manzi, D'Ottavio, Impellizzeri, Chaouachi, Chamari \& Castagna, 2010), basquetebol (Manzi et al., 2010), natação (Wallace, Slattery \& Coutts, 2009), e corrida (BorRESEN \& LAMBERT, 2008; MANZi et al., 2009b). Entretanto, este método ainda não foi utilizado juntamente com um

\section{Materiais e métodos}

Os atletas realizaram um teste de corrida incremental para determinar o limiar ventilatório (LV), ponto de compensação respiratória (PCR) e consumo máximo de oxigênio $\left(\mathrm{VO}_{2 \max }\right)$. Setenta e oito sessões de treinamento foram monitoradas diariamente por meio dos métodos PSE da sessão e baseado na FC antes da principal competição. Oito atletas completaram o período de observação. método de FC, com o objetivo de se correlacionar as respostas para as cargas de treinamento estimadas em jogadores jovens, semiprofissionais de futsal. Embora essa correlação já tenha sido verificada nas modalidades supracitadas, destaca-se que o futsal é uma modalidade intermitente que exige grande contribuição do metabolismo anaeróbio, com açôes mais intensas do que no futebol e outros esportes coletivos (Barbero-Alvarez, Soto, BarberoAlvarez \& Granda-Vera, 2008). Esse incremento da contribuição anaeróbia pode acarretar aumento da PSE, sem necessariamente alterar a resposta da FC (Foster, Florhaug, Franklin, Gottschall, Hirovatin, Parker, Doleshal \& Dodge, 2001). Assim, verificar essa correlação no futsal se faz necessário, pois a PSE já vem sendo utilizada na modalidade para quantificar a intensidade dos esforços (Milanez, Pedro, Moreira, Boullosa, Salle-Neto \& Nakamura, 2011).

Considerada uma importante estratégia para a preparação dos atletas para a temporada competitiva, a quantificação da distribuição da intensidade, a partir dos limiares ventilatórios, tem sido estudada em modalidades de endurance (Esteve-LanaO, Foster, Seiler \& Lucia, 2007; Esteve-Lanao, San Juan, Earnest, Foster \& Lucia, 2005; Seiler \& KJerland, 2006); no entanto, poucos estudos investigaram a distribuição da intensidade de treinamento em esportes coletivos intermitentes (Algroy, Hetlelid, Seiler \& Pedersen, 2011; Castagna, Impellizzeri, Chaouachi, Bordon \& MANZI, 2011). Para nosso conhecimento, ainda não há informações a respeito da distribuição da intensidade em sessões de treinamento típicas da modalidade futsal. Assim, os objetivos do estudo foram verificar a associação entre os métodos PSE da sessão e Lucia ${ }_{\text {TRIMP }}$ e quantificar a distribuição da intensidade de treinamento no futsal semiprofissional da categoria sub 18 .

\section{Amostra}

Inicialmente, 15 atletas semiprofissionais de futsal masculino foram selecionados para participar do estudo (media e DP; idade: $17 \pm 1$ ano; massa corporal: $70.4 \pm 6.5 \mathrm{~kg}$; estatura: $175 \pm 4 \mathrm{~cm}$ e IMC $23 \pm 2 \mathrm{~kg} \cdot \mathrm{m}^{-2}$ ). Foram excluídos do estudo os três goleiros, dois jogadores que sofreram lesões e dois 
atletas foram dispensados da equipe. Desta forma, oito atletas completaram o período de observação. Após receberem informações sobre os procedimentos do estudo, os sujeitos assinaram um termo de consentimento. Este estudo foi aprovado pelo Comitê de Ética em Pesquisa envolvendo seres humanos da Universidade Estadual de Londrina, protocolado sob o número 220/2010 em acordo com a resolução 196/96 do Conselho Nacional da Saúde.

\section{Procedimentos}

\section{Teste incremental}

O teste incremental de corrida em esteira rolante (Super ATL - Inbrasport ${ }^{\circledR}$, Brasil) foi iniciado a uma velocidade $6 \mathrm{~km} \cdot \mathrm{h}^{-1}$. A inclinação foi fixada em 1\% e os incrementos de $1 \mathrm{~km} . \mathrm{h}^{-1}$ foram realizados a cada minuto até a exaustão voluntária. Durante todo o teste progressivo, a FC foi registrada por meio de um cardiofrequencímetro (RS800, Polar Electro Oy, Finland). As trocas pulmonares gasosas foram registradas continuamente, respiração por respiração, por meio de um analisador de gases (Metalyzer 3B, CPX System, Germany), que foi calibrado antes de cada teste, de acordo com as instruções do fabricante. Os valores obtidos a partir da média aritmética de 20 segundos foram utilizados para as análises. $\mathrm{O}$ analisador de $\mathrm{O}_{2}$ e CO foi calibrado a partir de uma amostra de gás ambiente e de concentrações gasosas conhecidas de $\mathrm{O}_{2}(16 \%)$ e $\mathrm{CO}_{2}(5 \%)$, e o fluxo de gases para o aparelho também foi calibrado por meio de uma seringa com volume de três litros. Para que o valor de consumo máximo de oxigênio $\left(\mathrm{VO}_{2 \max }\right)$ fosse aceito, foram adotados os seguintes critérios: platô do $\mathrm{VO}_{2}$, razão de trocas respiratórias (RER) com valores acima de 1,10 e FC \pm 11 bpm da máxima prevista para a idade (Billat, Hill, Pinoteau, Petit \& Koralsztein, 1996). Ao menos dois desses critérios deveriam ser observados. O LV e o PCR foram determinados por dois avaliadores experientes que visualmente detectaram o aumento da relação $\mathrm{VE} / \mathrm{VO}_{2}$, sem o concomitante aumento da VE/ $\mathrm{VCO}_{2}$, e aumentos simultâneos desses parâmetros, respectivamente (LUCIA et al., 2003).

\section{Sessões de treinamento}

Os atletas realizavam entre três e quatro sessões de treinamento semanais, consistindo em treinamento técnico-tático (TT) e treinamento técnico-físico (TF). O componente técnico das sessões de treinos TT e TF era direcionado para a aquisição e refinamento de habilidades específicas do futsal. O componente tático das sessões de treinos TT visava definir o esquema de jogo da equipe por meio de simulaçóes de situações de defesa e ataque, e contra-ataque. Já os treinos físicos das sessões de treinos TF consistiram em: treinamentos com pesos livres e equipamentos isotônicos para aprimoramento da força geral e treinamentos em quadra com utilização de exercícios tracionados, corrida intervalada de alta intensidade e pliometria seguida de aceleração, para as capacidades de força rápida, potência aeróbia e potência/velocidade, respectivamente.

\section{Quantificação da distribuição \\ da intensidade de treinamento}

A quantificação da distribuição da intensidade de treinamento para cada sessão foi realizada por meio da resposta da FC dividida em três zonas (zona 1 = abaixo do $L V$, zona 2 = entre o $L V$ e PCR, e zona 3 = acima do PCR). Por meio de um programa comercial (Polar Pro Trainer 5.0, Polar Inc., Kempele, Finland), o tempo de permanência relativo em cada uma das três zonas foi calculado em termos percentuais à duração total da sessão de treinamento. A distribuição da intensidade de treinamento foi quantificada para os TT (número de sessões $=53$ ) e TF (número de sessões $=25$ ). Além disso, foi feita também para a somatória de todas as sessões, combinando TT e TF (TT + TF) (número de sessões $=78$ ).

\section{Quantificação da CT por meio do método PSE da sessão}

Para quantificação da CT por meio do método PSE da sessão, foi calculado o produto entre a duração de treinamento acumulado em minutos e o valor apontado na escala de PSE CR-10, modificada por Foster (1998) (FIGURA 1) sendo os resultados expressos em unidades arbitrárias (UA). A escala foi apresentada aos atletas 30 minutos após o final da sessão de treinamento quantificando, dessa forma, o esforço referente ao total da sessão. Todos os atletas foram familiarizados previamente com a escala de PSE CR-10 por pelo menos dois meses. 
TABELA 1- Escala de Borg (Borg, Hassmen \& LAGERSTROM, 1987) adaptada por FOSTER (1998).

\begin{tabular}{cc}
\hline Classificação & Descritor \\
\hline 0 & Repouso \\
1 & Muito, muito fácil \\
2 & Fácil \\
3 & Moderado \\
4 & Um pouco díficil \\
5 & Difícil \\
6 & - \\
7 & Muito difícil \\
8 & - \\
9 & - \\
10 & Máximo \\
\hline
\end{tabular}

\section{Quantificação da CT por meio do método de FC (Lucia TRIMP )}

Por meio da relação entre FC e tempo, durante o teste incremental, foram encontrados valores de FC relativos ao $L V$ e ao PCR. A partir desses valores de FC, três zonas de intensidades foram determinadas: zona 1: abaixo do LV, zona 2: entre o LV e PCR e zona 3: acima do PCR. Para o cálculo do LuciaTRIMP, foi realizada uma multiplicação do tempo acumulado em cada uma das três zonas pelo respectivo valor da mesma, e os resultados obtidos nas multiplicações foram somados e expressos em

\section{Resultados}

As variáveis fisiológicas analisadas no teste de corrida incremental máximo em esteira rolante realizado em laboratório são apresentadas na TABELA 1. O LV e o PCR ocorreram a 72 e $87 \%$ do $\mathrm{VO}_{2 \text { мах }}$, respectivamente.

O numero médio de sessōes monitoradas para cada jogador foi 10 (variando de sete a 14), e as unidades arbitrárias (UA) (LUCIA et al., 2003). A equação utilizada foi:

Lucia $_{\text {TRIMP }}=($ tempo na zona $1 \times 1)+($ tempo na zona $2 \times 2)+($ tempo na zona $3 \times 3)$

\section{Análise estatística}

Os dados de quantificação da distribuição da intensidade de treinamento foram analisados de forma subdividida em treinamentos TT, TF e combinando ambos os treinos TT+TF, sendo apresentados em média, desvio padrão e valores percentuais (\%). Depois de confirmada a normalidade da distribuição dos dados por meio do teste de Kolmogorov-Smirnov (com correção de Lilliefor), a correlação de Pearson foi utilizada para verificar a relação entre os métodos de quantificação de carga de treinamento. A relação entre os métodos foi analisada para a) cada sessão completada por cada jogador individualmente e b) cada tipo de treinamento completado pelos jogadores como um todo. Os dados estão apresentados em valores médios, desvio padrão e intervalo de confiança 95\% (IC 95\%). A correlação foi avaliada qualitativamente de acordo com as recomendaçōes de Hopkins, Marshall, Batterham e Hanin (2009): trivial $r<0,1$, pequena $r \geq 0,1$ e $<0,3$, moderada $r$ $\geq 0,3<0,5$, alta $r \geq 0,5 \mathrm{e}<0,7$, muito alta $\mathrm{r} \geq 0,7$ $e<0,9$, quase perfeita $r>0,9$ e perfeita $r=1$. Foi adotado $\mathrm{P}<0,05$. Todas as análises de dados foram realizadas com o programa Statistical Package for Social Sciences (SPSS), versão 17.0 para Windows.

correlaçôes individuais entre os métodos PSE da sessão e Lucia ${ }_{\text {TRIMP }}$ foram de alta a quase perfeita (TABELA 2).

O número total de sessões monitoradas foi $78 \mathrm{e}$ as correlações analisadas por tipos de treinamentos apresentaram magnitudes alta a quase perfeita, entre

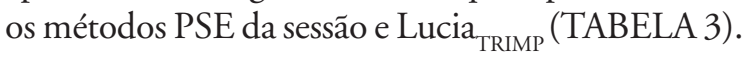


TABELA 2 - Variáveis fisiológicas dos jogadores $(\mathrm{n}=8)$.

\begin{tabular}{|c|c|}
\hline Variáveis & Média (DP) \\
\hline $\mathrm{VO}_{2 \max }\left(\mathrm{ml} \cdot \mathrm{kg}^{-1} \cdot \mathrm{min}^{-1}\right)$ & $61 \pm 4,9$ \\
\hline $\mathrm{LV}\left(\mathrm{ml} \cdot \mathrm{kg}^{-1} \cdot \mathrm{min}^{-1}\right)$ & $44 \pm 4,7$ \\
\hline PCR $\left(\mathrm{ml} \cdot \mathrm{kg}^{-1} \cdot \mathrm{min}^{-1}\right)$ & $53,3 \pm 3,7$ \\
\hline FCLV (bpm) & $163 \pm 14$ \\
\hline FCPCR (bpm) & $183 \pm 7$ \\
\hline FCmax (bpm) & $198 \pm 4$ \\
\hline Vel pico $\left(\mathrm{km} \cdot \mathrm{h}^{-1}\right)$ & $15 \pm 1$ \\
\hline Vel PCR $\left(\mathrm{km} \cdot \mathrm{h}^{-1}\right)$ & $12,7 \pm 1,6$ \\
\hline Vel LV $\left(\mathrm{km} \cdot \mathrm{h}^{-1}\right)$ & $9,9 \pm 1,4$ \\
\hline Vel PCR (\% Vel pico) & $85 \pm 13$ \\
\hline Vel LV (\% Vel pico) & $66 \pm 15$ \\
\hline
\end{tabular}

Consumo máximo de oxigênio $\left(\mathrm{VO}_{2}\right)$, limiar ventilatório (LV), ponto de compensação respiratória (PCR), frequência cardíaca no limiar ventilatório (FCLV), frequência cardíaca no ponto de compensação respiratório (FCPCR), frequência cardíaca máxima $\left(\mathrm{FC}_{\max }\right)$.

TABELA 3 - Correlações individuais entre os métodos PSE da sessão e Lucia ${ }_{\text {TRIMP }}$.

\begin{tabular}{|c|c|c|}
\hline Sujeitos & $\mathbf{N}$ & $\mathbf{R}$ \\
\hline 1 & 11 & $0,90^{* *}$ \\
\hline 2 & 7 & 0,64 \\
\hline 3 & 14 & $0,83^{* *}$ \\
\hline 4 & 12 & $0,83^{* *}$ \\
\hline 5 & 9 & $0,80^{* *}$ \\
\hline 6 & 9 & $0,84^{* *}$ \\
\hline 7 & 7 & $0,91^{* *}$ \\
\hline 8 & 9 & $0,75^{*}$ \\
\hline Min-max & $7-14$ & $0,64-0,91$ \\
\hline Média \pm DP & $10 \pm 2$ & $0,81 \pm 0,09$ \\
\hline IC 95\% & & $0,25-0,96$ \\
\hline
\end{tabular}

$\mathrm{N}$ = número de observações individuais; $r=$ coeficiente de correlação; min = mínimo; max = máximo IC $95 \%$ = intervalo de confiança de 95\%;

** nível de significância $P<0,01$;

* nível de significância $P<0,05)$.

TABELA 4 - Coeficientes de correlação entre os métodos PSE da sessão e Lucia ${ }_{\text {TRIMP }}$ separados por tipos de treinamento.

\begin{tabular}{lcc}
\hline \multicolumn{1}{r}{ Tipos de treinamento } & n & r \\
\hline TF & 25 & $0,81^{* *}$ \\
TT & 53 & $0,62^{* *}$ \\
TT + TF & 78 & $0,75^{* *}$ \\
\hline
\end{tabular}

TF = técnico-físico; TT = técnico-tático; $\mathrm{n}$ = número de sessões de treinamento monitoradas;

$r=$ coeficiente de correlação;

** nível de significância $\mathrm{P}<0,01$.
A intensidade das sessões de treinamentos TT $+\mathrm{TF}$ apresentou a seguinte distribuição 76, 18 e 6\% abaixo do LV, entre LV e PCR e acima do PCR respectivamente. Durante as sessóes de treinamento TT isoladamente, a distribuição das intensidades foi 73 ,
20 e 7\% abaixo do LV, entre o LV e PCR e acima do $\mathrm{PCR}$, respectivamente, enquanto que a distribuição das intensidades das sessóes de TF foi 80, 14 e 6\% entre o LV, ente o LV e PCR e acima do PCR, respectivamente. Esses resultados são apresentados na FIGURA 2. 

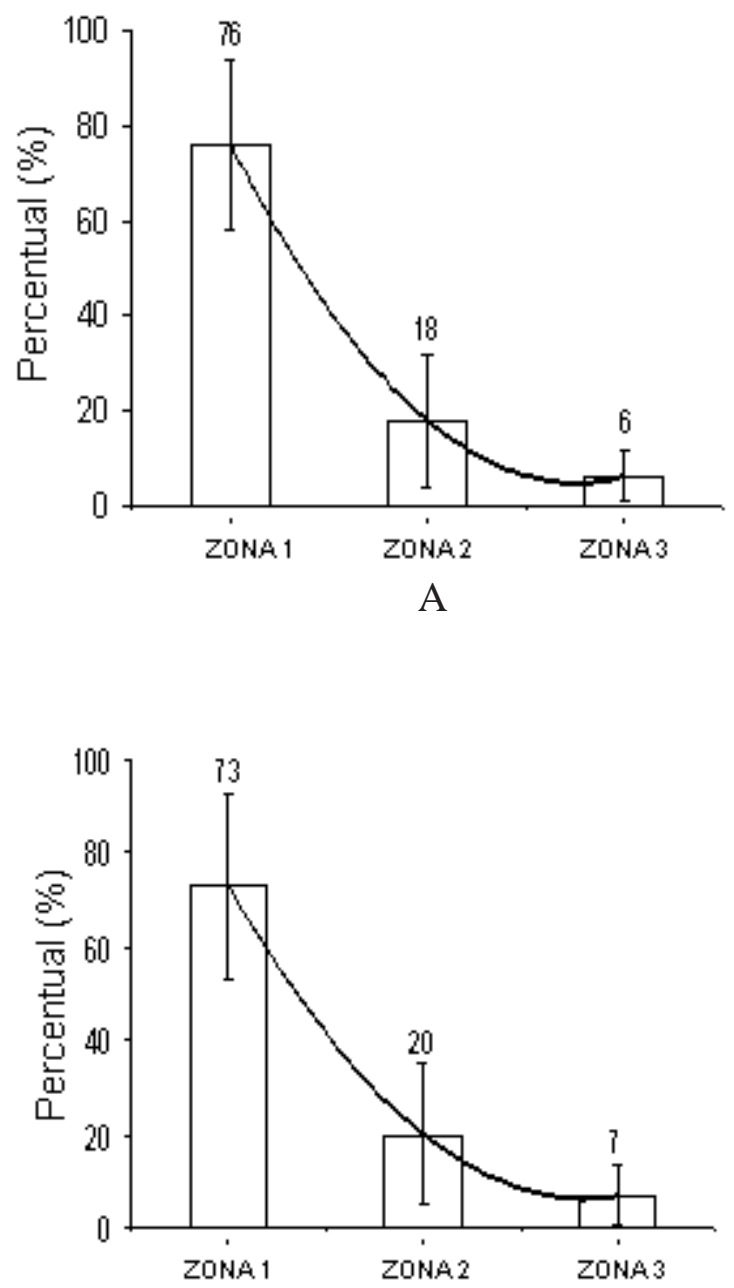

B

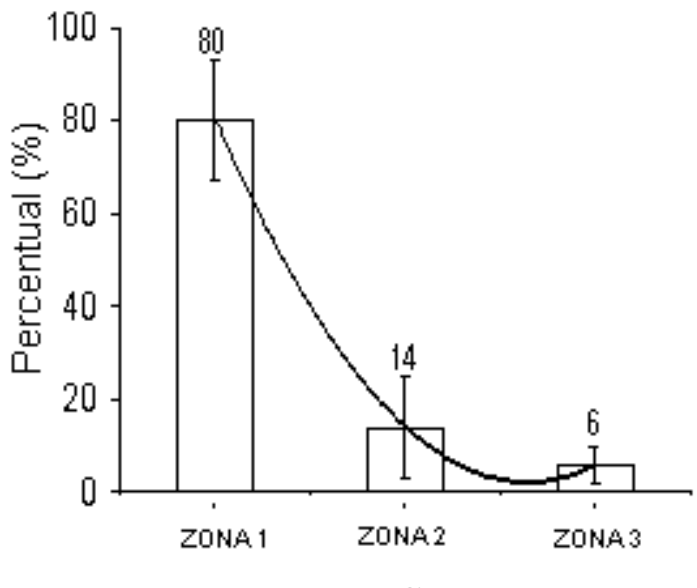

C

FIGURA 1 - Quantificação da distribuição das cargas de treinamento técnico-tático + técnico-físico (A), técnicotático (B) e técnico-físico (C). 


\section{Discussão}

Os principais resultados obtidos neste estudo foram: 1) alta associação encontrada entre os métodos de quantificação de CT, PSE da sessão e Lucia ${ }_{\text {TRIMP }}$ na modalidade futsal e 2) a quantificação da intensidade das CT durante várias sessões da pré-temporada apresentou um padrão de distribuição decrescente, onde os atletas treinavam maior volume na intensidade abaixo do LV, intermediário entre LV e PCR, e menor volume acima de PCR. Houve correlações de magnitudes alta a quase perfeita entre os métodos de quantificação de CT, PSE da sessão e Lucia ${ }_{\text {TRIMP }}$ para cada um dos oito jogadores avaliados (TABELA 2), e também quando analisados os tipos de treinamento para os jogadores como um todo (TABELA 3).

Desenvolvido originalmente para quantificar CT ou a carga competitiva em modalidades de endurance, Lucia ${ }_{\text {TRIMP }}$ considera a resposta FC em teste progressivo para encontrar valores de FC relativos ao LV e PCR. Foster (1998) encontrou alta correlação entre PSE da sessão e o método Lucia $_{\text {TRIMP }}(r=0,75-0,90)$ para esportes de endurance. Em relação às modalidades intermitentes, os métodos de quantificação de CT baseados em impulsos de treinamento (TRIMP), que integram volume e intensidade a partir da resposta da FC, tal como, o método Lucia TRIMp têm sido criticado com frequência na literatura (AleXIOU \& CoutTs, 2008; BORRESEN \& LAMBERT, 2008; IMPELLIZZERI et al., 2004; Wallace, Slattery \& Coutts, 2009). Entretanto, na falta de um método padrão ouro, a correlação entre os métodos baseados na resposta da PSE e FC tem sido amplamente utilizada tanto para as modalidades de endurance (Foster 1998; MANZI et al., 2009b; Wallace, Slattery \& Coutts, 2009), quanto para as modalidades intermitentes(AlEXIOU \& CoutTs, 2008; Impellizzeri et al., 2004; MilaNEZ \& PEDRO, in press).

Os resultados de correlações individuais obtidos no presente estudo $(r=0,64-0,91)$ correspondiam a um coeficiente de explicação médio de $67 \%$, corroborando estudos anteriores que reportaram altas correlações entre os métodos PSE da sessão e Lucia $_{\text {TRIMP }}$ nas modalidades de futebol masculino $(\mathrm{r}=0,61-0,85)$ (Impellizzeri et al., 2004) e caratê (Milanez \& Pedro, in press) $(\mathrm{r}=0,71)$. Assim, com base nos resultados do presente estudo, bem como de estudos prévios, é possível afirmar que a PSE da sessão pode ser considerada um método viável para quantificar CT em modalidades intermitentes, tais como as acima citadas, incluindo o futsal.
No presente estudo, ao considerarmos os resultados separados por tipo de treinamento, as correlações entre os métodos PSE da sessão e Lucia foram maiores para os treinos TF $(r=0,81) \mathrm{em}$ comparação com os treinos TT $(r=0,62)$. Quando combinados (TT+TF), a correlação entre os métodos foi de 0,75 . Tal correlação foi maior do que a verificada em estudo anterior (AlEXIOU \& CouTTS, (2008), o qual mostrou correlaçôes baixas e moderadas nesse tipo de treinamento $(r=0,25-0,52)$, entre PSE da sessão e os métodos de quantificação das CT baseados na resposta da FC. Esse resultado não era esperado, dada a maior sobrecarga neuromuscular do TF (pesos e pliometria), quando comparado ao sistema cardiovascular. Dessa forma, a FC poderia não representar magnitude da CT imposta. No entanto, uma característica poderia justificar esse achado; as sessóes de treinamentos com pesos/ pliometria foram realizadas em associação com os treinos técnicos, e quantificados em conjunto. Assim, é possível que essse tipo de treinamento TF tenha gerado maior variação nos valores de $\mathrm{FC}$ e PSE, contribuindo para correlações mais fortes entre os métodos de quantificação das CT.

A baixa correlação entre os métodos baseados na resposta de PSE e FC não significa, necessariamente, uma limitação do método PSE da sessão. O critério adotado com base na FC pode não refletir, fielmente, a carga interna quando as sessões de treinamento envolvem esforços estocásticos e de alta intensidade (NAKamura, Moreira \& AOKI, 2010), pois quantificar a CT a partir das respostas cardiovasculares em atividades intermitentes com elevada contribuição do metabolismo anaeróbio, pode não ser adequado. De acordo com Borresen e LAMBERT (2008) os métodos baseados na resposta da FC são limitados para avaliar exercícios de alta intensidade, tais como, treinamentos intervalados de alta intensidade, inclusive treinamentos pliométricos e treinamentos com pesos (Borresen \& Lambert, 2008; Foster et al., 2001). Corroborando essa hipótese, DAY, BRICE e Foster (2004) reportaram forte correlação entre PSE da sessão e diferentes intensidades externas, 50, 70 e 90\% de uma repetição máxima (método padrão ouro para avaliação da força), durante treinamento com pesos.

Em relação à quantificação da distribuição da intensidade das cargas, nossos resultados mostraram que o futsal apresenta um padrão de distribuição da intensidade de treinamento que denominamos decrescente. Esse modelo é diferente dos dois padrões 
básicos (modelo de treinamento entre os limiares e modelo de treinamento polarizado) descritos anteriormente para modalidades de endurance (ESTEVELANAO et al., 2005, 2007; Seiler \& KJerland, 2006), mas similar ao do futebol (CASTAGNA et al., 2011). Porém, esse não foi um estudo experimental, no qual comparamos o efeito de diferentes distribuições de intensidade de treinamento sobre o aumento do rendimento. Dessa forma, não podemos inferir sobre a eficácia dessa distribuição de treinamento sobre parâmetros de adaptação fisiológica.

Poucos estudos analisaram o padrão de distribuição da intensidade de treinamento em modalidades intermitentes. CASTAGNA et al. (2011) verificaram que a distribuição da intensidade de treinamento de jogadores profissionais de futebol compreendia $73 \%$ abaixo do LV, 19\% entre LV e PCR e 8\% acima do PCR. Ainda no futebol, esse padrão de distribuição de intensidade de treinamento foi reportado também por Algroy et al. (2011) como sendo 73, 18 e 9\% nas intensidades abaixo do LV, entre LV e PCR e acima de PCR respectivamente. Ambos os padróes diferiram ligeiramente da distribuição polarizada em formato de "U" e se assemelharam ao modelo de distribuição encontrado no presente estudo. CASTAGNA et al. (2011) verificaram que uma distribuição de treinamento decrescente resultou em adaptações favoráveis em variáveis aeróbias submáximas para jogadores de futebol. Mostraram ainda que cargas nas intensidades superiores a PCR se associavam a alteraçôes favoráveis nos próprios limiares metabólicos.

Ao analisarmos a distribuição das intensidades separadas por tipo de treinamento (TF, TT, TT+TF), embora tenha apresentado o mesmo padrão (decrescente), o TT mostrou-se ligeiramente mais intenso (73, 20 e 7\% - abaixo da LV, entre LV e PCR e acima de PCR, respectivamente) do que para TF $(80,14$ e 6\%). No presente estudo, as sessões de TT foram utilizadas, sobretudo, para a aquisição de habilidades motoras, mas também, estrategicamente elaboradas com açôes de altas intensidades para simular as situaçôes de jogo.

Assumimos a limitação de utilizar um modelo baseado em limiares e decorrente de um teste

\section{Considerações finais}

De acordo com os resultados encontrados no presente estudo, a PSE da sessão parece ser um método adequado para auxiliar os técnicos e preparadores incremental, cíclico, em esteira, para quantificar a distribuição da intensidade no futsal. Embora existam evidências de que a FC nos limiares metabólicos durante teste progressivo intermitente de campo (mais específico para esportes coletivos) ocorra na mesma faixa de valores encontrados em teste progressivo contínuo em esteira (BuCHHEIT, Al Haddad, Millet, Lepretre, NeWTON \& AhMAIDI, 2009), tais valores poderiam representar diferentes domínios fisiológicos, representando diferentes percentuais da FC máxima, ou da velocidade máxima, atingidas.

Outra limitação do presente estudo foi quantificar a CT a partir da duração total em cada zona de treinamento. Embora este procedimento tenha sido adotado em estudos anteriores com futebol (ALGROY et al., 2011; CASTAGNA et al., 2011), e caratê (MiLAneZ, Dantas, Christofaro \& Fernandes, in press), a utilização deste tipo de estratégia em modalidades intermitentes tem sido criticada, uma vez que os intervalos de recuperação entre os esforços poderiam reduzir a FC média e, consequentemente, subestimar a sobrecarga interna causado pelo trabalho intervalado de alta intensidade (Algroy et al., 2011). Para modalidades intermitentes, sugere-se a utilização do método baseado na PSE proposto por SEILER e KJERLAND (2006), pois este método pode refletir melhor o real impacto causado pelos repetidos períodos de trabalho intervalado em alta intensidade na carga total de treinamento (Algroy et al., 2011).

Embora CASTAGNA et al. (2011) tenham reportado um padrão de distribuiçãao de intensidade semelhante ao modelo de treinamento decrescente do presente estudo, não podemos afirmar que as melhoras nas variáveis aeróbias submáximas, por eles encontrados para jogadores de futebol, se reproduziriam em jogadores de futsal. Os atletas do presente estudo são semiprofissionais, estavam em período de pré-temporada, e treinavam entre 1,5 e $3 \mathrm{~h}$ por dia, três a quatro vezes por semana. Assim, estudos experimentais comparando diferentes modelos de distribuições de intensidades, tais como, modelo no limiar, modelo polarizado e modelo decrescente, em diferentes fases do ciclo de treinamento, necessitam ainda ser realizados.

físicos na quantificação das CT no futsal semiprofissional da categoria sub 18. Além disso, o padrão de distribuição da intensidade de treinamento descrita 
nesse estudo difere dos modelos de distribuição (entre os limiares e polarizado) normalmente descritos para modalidades de endurance, sugerindo a existência de um terceiro modelo de distribuição de treinamento em formato decrescente, corroborando resultados prévios com o futebol (Algroy et al., 2011; CASTAGnA et al., 2011). Ou seja, parece que no futsal semiprofissional da categoria sub 18 os atletas treinam em maior volume na intensidade abaixo do LV, intermediário entre LV e PCR, e menor volume acima de PCR. Estudos futuros devem determinar qual a dose ideal de imposição de cargas em cada faixa de intensidades no futsal, uma vez que já há demonstração preliminar que o volume de treino na faixa acima da PCR favorece adaptaçôes aeróbias em jogadores de futebol.

\begin{abstract}
Relationship between methods of training load quantification based on perception of effort and heart rate in young futsal players
\end{abstract}

The aims of this study were to verify the association between the methods of training load quantification session-RPE and training impulse -proposed by Lucia $\left(\right.$ Lucia $\left._{\text {TRIMP }}\right)$ - and to describe the training intensity distribution in under-18 semi-professional futsal. Fifteen male players (mean and SD; age: $17 \pm 1$ years; body mass: $70.4 \pm 6.5 \mathrm{~kg}$; height: $175 \pm 4 \mathrm{~cm}$ and BMI $23 \pm 2 \mathrm{~kg} . \mathrm{m}^{2}$ ) performed an incremental treadmill test to determine the ventilatory threshold (VT), respiratory compensation point (RCP), and maximal oxygen consumption $\left(\mathrm{VO}_{2 \max }\right)$. Only eight athletes had their training loads quantified by means of session-RPE and Lucia ${ }_{\text {TRIMP }}$ methods over a total of 78 training sessions before the main competition of the season. High to almost perfect correlations $(r=0.64-0.91)$ were found between session-RPE and Lucia ${ }_{\text {TRIMP }}$ methods. The distribution of the training intensity was, respectively, 76, 18 e $6 \%$ of training duration below VT (zone 1), between VT and RCP (zone 2), and above RCP (zone 3). The session-RPE method was highly associated with an objective method of training load quantification. Furthermore, the training sessions of a semi-professional under-18 futsal team showed a decreasing training intensity distribution.

UNITERMS: Ventilatory threshold; Respiratory compensation point; Internal training load; Team sports.

\title{
Referências
}

ALEXIOU, H.; COUTTS, A.J. A comparison of methods used for quantifying internal training load in women soccer players. International Journal of Sports Physiology and Performance, Champaign, v.3, n.3, p.320-30, 2008.

ALGROY, E.A.; HETLELID, K.J.; SEILER, S.; PEDERSEN, J.I.S. Quantifyng training intensity distribuition in a group of norwegian professional soccer players Intenational Journal of Sports Physiology and Performance, Champaign, v.6, p.70-81, 2011. BANISTER, E. Modeling elite athletic performance. In: MacDOUGALL, J.D.; WENGER, H.A.; GREEN, H.J. Physiological testing of the high-performance athlete. 2nd. ed. Champaign: Human Kinetics, 1991. p.403-25. BARBERO-ALVAREZ, J.C.; SOTO, V.M.; BARBERO-ALVAREZ, V.; GRANDA-VERA, J. Match analysis and heart rate of futsal players during competition. Journal of Sports Sciences, London, v.26, n.1, p.63-73, 2008.

BILLAT, V.L.; HILL, D.W.; PINOTEAU, J.; PETIT, B.; KORALSZTEIN, J.P. Effect of protocol on determination of velocity at $\mathrm{VO}_{2 \max }$ and on its time to exhaustion. Archives of Physiology and Biochemistry, Lisse, v.104, n.3, p.313-21, 1996. BORG, G.; HASSMEN, P.; LAGERSTROM, M. Perceived exertion related to heart rate and blood lactate during arm and leg exercise. European Journal Applied Physiology and Occupational Physiology, Berlin, v.56, n.6, p. 679-85, 1987. BORRESEN, J.; LAMBERT, M.I. Quantifying training load: a comparison of subjective and objective methods. International Journal of Sports Physiology and Performance, Champaign, v.3, n.1, p.16-30, 2008.

BUCHHEIT, M.; AL HADDAD, H.; MILLET, G.; LEPRETRE, P.; NEWTON, M.; AHMAIDI, S. Cardiorespiratory and cardiac autonomic responses to 30-15 intermittent fitness test in team sport players. Journal of Strength and Condition Research, Champaign, v.23, n.1, p.93-100, 2009. 
CASTAGNA, C.; IMPELLIZZERI, F.M.; CHAOUACHI, A.; BORDON, C.; MANZI, V. Effect of training intensity distribution on aerobic fitness variables in elite soccer players: a case study. Journal of Strength and Condition Research, Champaign, v.25, n.1, p.66-71, 2011.

DAY, M.M.; BRICE, MR.; FOSTER, C. Monitoring exercise intensity during resistance training using the session RPE scale. Journal of Strength and Condition Research, Champaign, v.18, p. 353-358, 2004.

EDWARDS, S. The heart hate monitor book. Sacramento: FeeFleet, 1993.

ESTEVE-LANAO, J.; FOSTER, C.; EILER, S.; LUCIA, A. Impact of training intensity distribution on performance in endurance athletes. Journal of Strength and Condition Research, Champaign v.21, n.3, p.943-49, 2007.

ESTEVE-LANAO, J.; SAN JUAN, A.F.; EARNEST, C.P.; FOSTER, C.; LUCIA, A. How do endurance runners actually train? Relationship with competition performance. Medicine \& Science in Sports \& Exercise, Madison, v.37, n.3, p.496-504, 2005. FOSTER, C. Monitoring training in athletes with reference to overtraining syndrome. Medicine \& Science in Sports \& Exercise, Madison, v.30, n.7, p. 1164-1168, 1998.

FOSTER, C.; FLORHAUG, J.; FRANKLIN, J.; GOTTSCHALL, L.; HIROVATIN, L.; PARKER, S.; DOLESHAL, P.; DODGE, C. A new approach to monitoring exercise training. Journal of Strength and Condition Research, Champaign, v.15, p.109-15, 2001.

FOSTER, C.; HECTOR, L.L.; WELSH, R.; SCHRAGER, M.; GREEN, M.A.; SNYDER, A.C. Effects of specific versus cross-training on running performance. European Journal Applied Physiology and Occupational Physiology, Berlin, v.70, n.4, p.367-72, 1995 .

HOPKINS, W.; MARSHALL, S.; BATTERHAM, A.; HANIN, J. Progressive statistics for studies in sports medicine and exercise science. Medicine \& Science in Sports \& Exercise, Madison, v.41, n.1, p.3, 2009.

IMPELLIZZERI, F.M.; RAMPININI, E.; COUTTS, A.J.; SASSI, A.; MARCORA, S.M. Use of RPE-based training load in soccer. Medicine \& Science in Sports \& Exercise, Madison, v.36, n.6, p.1042-7, 2004.

LAMBERT, M.I.; BORRESEN, J. Measuring training load in sports. International Journal of Sports Physiology and Performance, Champaign, v.5, n.3, p. 406-411, 2010.

LUCIA, A.; HOYOS, J.; SANTALLA, A.; EARNEST, C.; CHICHARRO, J.L. Tour de France versus Vuelta a Espana: which is harder? Medicine \& Science in Sports \& Exercise, Madison, v.35, n.5, p. 872-878, 2003.

MANZI, V.; CASTAGNA, C.; PADUA, E.; LOMBARDO, M.; D’OTTAVIO, S.; MASSARO, M.; VOLTERRANI, M.; IELLAMO, F. Dose-response relationship of autonomic nervous system responses to individualized training impulse in marathon runners. American Journal of Physiology: Heart and Circulatory Physiology, Bethesda, v.296, n.6, p. 1733-40, 2009a. MANZI, V.; D'OTTAVIO, S.; IMPELLIZZERI, F.M.; CHAOUACHI, A.; CHAMARI, K.; CASTAGNA, C. Profile of weekly training load in elite male professional basketball players. Journal of Strength and Condition Research, Champaign, v.24, n.5, p.1399-406, 2010.

MANZI, V.; IELLAMO, F.; IMPELLIZZERI, F.; D’OTTAVIO, S.; CASTAGNA, C. Relation between individualized training impulses and performance in distance runners. Medicine \& Science in Sports \& Exercise, Madison, v.41, n.11, p.2090-6, 2009b.

MEEUSEN, R.; DUCLOS, M.; GLESSON, M.; RIETJENS, G.; STEINACKER, J.; URHAUSEN, A. Prevention, diagnosis and treatment of the Overtraining Syndrome: ECSS position statement task force. European Journal of Sport Science, Champaign, v.6, p.1-14, 2006.

MILANEZ, V.F.; DANTAS, J.L.; CHRISTOFARO, D.G.D.; FERNANDES, R.A. Resposta da frequência cardíaca durante sessão de treinamento de karatê. Revista Brasileira de Medicina do Esporte, São Paulo, in press.

MILANEZ, V.F.; PEDRO, R.E. Aplicação de diferentes métodos de quantificação de cargas durante uma sessão de treinamento de karate. Revista Brasileira de Medicina do Esporte, São Paulo, in press.

MILANEZ, V.F.; PEDRO, R.E.; MOREIRA, A.; BOULLOSA, D.A.; SALLE-NETO, F.; NAKAMURA, F.Y. The role of aerobic fitness on session-rating of perceived exertion in futsal players. International Journal of Sports Physiology and performance, Champaign, v.6, p.358-66, 2011.

NAKAMURA, F.Y.; MOREIRA, A.; AOKI, M.S. Monitoramento da carga de treinamento: a percepção subjetiva do esforço da sessão é um método confiável? Revista da Educação Física/UEM, Maringá, v.21, n.1, p.1-11, 2010.

NEDERHOF, E.; ZWERVER, J.; BRINK, M.; MEEUSEN, R.; LEMMINK, K. Different diagnostic tools in nonfunctional overreaching. International Journal of Sports Medicine, Stuttgart, v.29, n.7, p.590-7, 2008.

SEILER, K.S.; KJERLAND, G.O. Quantifying training intensity distribution in elite endurance athletes: is there evidence for an "optimal" distribution? Scandinavian Journal of Medicine and Science in Sports, Copenhagen, v.16, n.1, p.49-56, 2006. 
STAGNO, K.M.; THATCHER, R.; van SOMEREN, K.A. A modified TRIMP to quantify the in-season training load of team sport players. Journal of Sports Sciences, London, v.25, n.6, p.629-34, 2007.

SUZUKI, S.; SATO, T.; MAEDA, A.; TAKAHASHI, Y. Program design based on a mathematical model using rating of perceived exertion for an elite Japanese sprinter: a case study. Journal of Strength and Condition Research, Champaign, v.20, n.1, p.36-42, 2006.

TAHA, T.; THOMAS, S.G. Systems modelling of the relationship between training and performance. Sports Medicine, Auckland, v.33, n.4, p. 1183-1188, 2003.

WALLACE, L.K.; SLATTERY, K.M.; COUTTS, A.J. The ecological validity and application of the session-RPE method for quantifying training loads in swimming. Journal of Strength and Condition Research, Champaign, v.23, n.1, p.33-8, 2009.

Vinicius Flávio Milanez

R. Belo Horizonte, 99 - apto. 704

19650-060 - Londrina - PR - BRASIL

e-mail: viniciunesp@hotmail.com
Recebido para publicação: 30/05/2011

1a. Revisão: 21/ 09/2011

2a. Revisão: 16/11/2011

Aceito: 18/11/2011 